\title{
Comunidade e tensão na fronteira agrária paulista (Limeira, década de 1840)
}

Carlos Alberto Medeiros Lima*

Resumo: O caso de Limeira, SP, e da fronteira Oeste da província durante o segundo quarto do século XIX é útil para capturar uma série de especificidades desse período balizado por fortes mudanças nas condições institucionais para o acesso à terra e à propriedade de escravos, além da instabilidade política. Usam-se listas de habitantes e registros de óbito e batismo para capturar as condições dessa fronteira canavieira que já apresentava sinais de transição para a concentração no café que a caracterizaria mais tarde. Nesse quadro de forte, apesar de acidentado, crescimento da população livre e escrava, o recurso intenso ao tráfico de escravos manifestava-se ao lado de sinais de que contingentes demográficos eram perdidos para áreas mais a Oeste. Combinava-se igualmente com um certo ímpeto de construção comunitária e com a preservação de mecanismos de reprodução de casas senhoriais. Nesse quadro, aprofundava-se a desigualdade entre os livres e minguavam alguns mecanismos de mobilidade social. Paralelamente, aumentava a distância, no terreno das sociabilidades hierárquicas, das pessoas livres frente aos escravos.

Palavras-chave: Escravidão. Fronteira agrária. Província de São Paulo. Século XIX. Lavoura canavieira. Cafeicultura.

O objetivo deste trabalho é avançar algumas percepções acerca do instável intervalo da história brasileira estendido de 1830 a 1850 .

"Doutor em História Social pela Universidade Federal do Rio de Janeiro - UFRJ. Professor associado do Departamento de História da Universidade Federal do Paraná - UFPR. Bolsista de produtividade em pesquisa do CNPq. E-mail: carlima3@gmail.com

Anos 90, Porto Alegre, v. 23, n. 44, p. 231-263, dez. 2016 
Além da instabilidade política e de conflitos sociais de grande alcance, ocorreram no período outros deslocamentos geradores de turbulência, especialmente no terreno das relações entre grupos senhoriais e o processo de consolidação estatal. Muita instabilidade decorreu igualmente de fatores de crise insertos nos mecanismos da oferta de terras e escravos, como se verá. Ao mesmo tempo, durante esse período ganharam corpo processos, instituições, grupos e atividades que viriam a ter enorme importância em momentos subsequentes da história brasileira. Seriam muito modificados tanto pelo "tempo saquarema" quanto pela "conciliação" subsequente, mas durariam (MATTOS, I., 1987). Podem-se citar a esse respeito atividades econômicas e a projeção regional dessas atividades - como o alargamento da expansão agrária para o Oeste Paulista e a definição da grande faixa organizada ao redor do Vale do rio Paraíba. Do mesmo modo, instituições criadas nessa época resistiram, embora com modificações, às mudanças posteriores: partidos políticos e instituições militares como a Guarda Nacional, além de agências provinciais, imperiais - como a reorganização dos gabinetes ministeriais - e judiciárias. Para tirar mais lições relativas a esse intervalo, pretende-se detectar mais processos na parcela da fronteira agrária paulista que possa ser caracterizada como marcada pela transição da cana para o café. Como ela ganharia centralidade, além de capacidade de estruturar alguma coisa no nível imperial, pode ser que tenha comunicado algo de novo a esses ambientes mais amplos quando eles estivessem estabelecidos.

Quanto ao avanço da fronteira, os estudos sobre a agricultura brasileira no longo prazo chamaram a atenção para a pluralidade de condições sociais envolvidas nessa expansão, desde a compreensão sobre o envolvimento de pobres nesses movimentos durante o século XIX (MATTOS, H., 1995), até as apreciações sobre a combinação de frentes pioneiras e frentes de expansão no século XX (MARTINS, 1996). Isso se dava no intervalo estudado, ao lado da circunstância de outro arranjo de oferta de fatores encontrar-se bastante desorganizado no mesmo período, qual seja a oferta de escravos africanos. De modo análogo ao que deve ter-se passado com o acesso à terra - expansão com conflitos -, o tráfico de escravos atingiu seus ápices (não sustentados, isto é, entremeados de baixas profundas) em momentos específicos do fim dos anos 1840, mas em meio a 
um sentido geral de desorganização, com flutuações muito maiores que as tradicionalmente verificadas, preços oscilantes (mesmo sem chegar aos extremos do período posterior à abolição definitiva do comércio de almas em 1850 - sobre isso se deve consultar MOTTA, J., 2012) e segurança bastante variável quanto à posse.

Ainda quanto ao intervalo iniciado em 1830, novas fronteiras estavam em processo de abertura, inclusive no Sudeste. Além disso, ocorreram importantes deslocamentos produtivos e regionais na agricultura da região, com muita passagem do foco na cana para a ênfase no café.

Atentar para fronteiras formadas em uma situação como essa dá acesso a questões importantes sobre o país. Até os anos 1820, áreas novas se formavam podendo contar com mercado ampliado, terras acessíveis e oferta crescente de escravos obtidos a baixo preço. O tráfico só crescia e a regulação do acesso à terra por intermédio de sesmarias não chegava a impedir nem a posse, nem transações com terra no mercado.

Após 1850, a oferta de terras transitou para situação de constrangimento, quanto a grupos mais depauperados, mas de encaminhamento para a monopolização, no que tocava a elites sociais, de modo que esses segmentos experimentaram, respectivamente, restrição e abundância. A monopolização por grupos restritos passou a ser a situação também no tocante à posse de escravos. $\mathrm{O}$ produto principal - o café - não se associava a economias de escala e tinha mercado crescente, mas os constrangimentos referentes aos dois aspectos anteriores - terra e escravos - restringiam o número dos que podiam tirar partido dessas oportunidades de crescimento.

No meio do caminho esteve o intervalo 1830-1850. Quanto aos produtos e seus mercados, o açúcar executou uma espécie de parábola, com forte crescimento até 1840 e a derrota para a concorrência cubana a partir de então, ao passo que o café prosseguiu em marcha ascendente, embora mais suave do que antes de 1830 e depois de 1850. Quanto à terra, havendo disposição para enfrentar conflitos, a sensação entre os que migravam para a fronteira deve ter sido a de que algo foi "destampado". Mais ambígua era a conformação do mercado de escravos, caracterizando-o flutuações inusitadas de volumes, preços e segurança quanto ao arranjo institucional da posse. 
Esse trabalho aborda a vila de Limeira a partir de uma lista nominativa da segunda metade da década de 1840 arquivada no Arquivo Público do Estado de São Paulo (doravante APESP) como Maços de população ([18--?]). Em verdade, essa fonte precisa ser tomada com cuidado. A abordagem sistemática dos censos paulistas adverte que eles perderam qualidade nessa época, passando a ser realizados por juízes de paz, que, além de algum desleixo, tinham mandatos fixos (MARCÍLIO, 2000, p. 49; COSTA; NOZOE, 1991, p. 271-284). Além disso, como essa lista não está datada convenientemente, fizeram-se cruzamentos nominativos com outros censos e com assentos de batismo e óbito para atribuir uma datação aproximada, o que apontou para meados dos anos 1840, ou pouco depois. Acresce que os recenseadores foram negligentes em marcar em que ponto da lista terminava um domicílio e começava outro, levando à prática de considerar que um novo domicílio iniciava sempre que aparecesse a indicação de uma ocupação.

Vem sendo considerado insuficiente o uso das informações de recenseamentos isolados (MARCÍLIO, 2000; LUNA; KLEIN, 2005). Mas alguns problemas específicos de investigação ainda precisam ser abordados dessa maneira, especialmente quando se trata de observar municípios criados posteriormente a 1830, pois é necessário cruzar as informações censitárias com outras fontes, sendo remota a chance de consultar recenseamentos sucessivos de um mesmo local.

\section{Limeira}

Desmembrada de Piracicaba (então chamada Constituição) em 1842, Limeira ganhou notoriedade na historiografia por abrigar as unidades canavieiras e depois cafeeiras de Nicolau Pereira de Campos Vergueiro, Bento Manoel de Barros e Gertrudes Galvão de Oliveira Lacerda (WITTER, 1996, p. 133-144; DEAN, 1977, p. 45; SAMARA, 1989, p. 130-140). Algumas das maiores escravarias na lista nominativa apareciam associadas à palavra engenho, mas a transição para a cafeicultura já devia estar adiantada. É possível 
que se fizesse referência, nas listas, à posição social e política e as privilégios dos senhores de engenho. De fato, entre 1807 e 1833 parecem ter vigorado, quanto aos senhores de engenhocas paulistas, as tradicionais proteções contra execuções. Isso podia referir-se a impedimentos quanto à desintegração de unidades, à limitação das execuções apenas a rendimentos, e não a benfeitorias, ou a outras proteções da camada de proprietários frente a negociantes. Apesar de cambiante, essa legislação certamente influía muito em querelas judiciais e nas expectativas quotidianas. Nessas ocasiões, ela devia parecer significar que senhores de engenho gozavam de salvaguardas pessoais contra execuções. Isso, elaborado quanto ao Nordeste açucareiro durante os séculos XVII e XVIII (SCHWARTZ, 1988, p. 179 et seq.; FERLINI, 1988, p. 193-197), foi estendido ao Rio de Janeiro no século XVIII e, entre 1807 e 1809, a São Paulo (PETRONE, 1968, p. 34-136). O "privilégio da integridade", de 1833, possibilitou a execução dos senhores, não mais restringindo-a aos rendimentos, mas a partir de então podendo afetar também as benfeitorias. No entanto, as quebras de unidades produtivas ficavam proibidas (PETRONE, 1968, p. 134-136; OLIVEIRA, A., 1887, p. 22). Talvez isso explique a tendência à identificação, no censo, entre grandes unidades escravistas e engenhos.

Quanto ao café, segundo Dean (1977, p. 45), "Sementes vindas do Rio de Janeiro tinham sido plantadas em Campinas já em 1817, e em Limeira, na plantação Ibicaba, de Vergueiro, em 1828”. Outras pessoas adquiriram mudas dessas experiências, de modo que alguns fazendeiros de Rio Claro tinham pés produzindo em 1835. "Somente após 1840 se deu início ao plantio em larga escala de café no Oeste Paulista, de Campinas até Rio Claro” (DEAN, 1977, p. 45), e sabe-se que esta última área não chegou a alcançar os níveis limeirenses de meados da década de 1850, embora depois os ultrapassasse com folga. Rio Claro, em 1854, com 6564 habitantes, produziu 99670 arrobas de café. As condições de Limeira, diferentemente, com seus 5045 moradores, permitiram que se produzissem 121800 arrobas. Em outras palavras, população $23 \%$ menor e produção cafeeira $22 \%$ superior (MILLIET, 1938, p. 69). Os registros de óbito permitem enfatizar e matizar a tendência ao crescimento da população de Limeira (Gráfico 1). 


\section{Gráfico 1 - óbitos de livres e escravos em Limeira (1837-1859) - números absolutos}

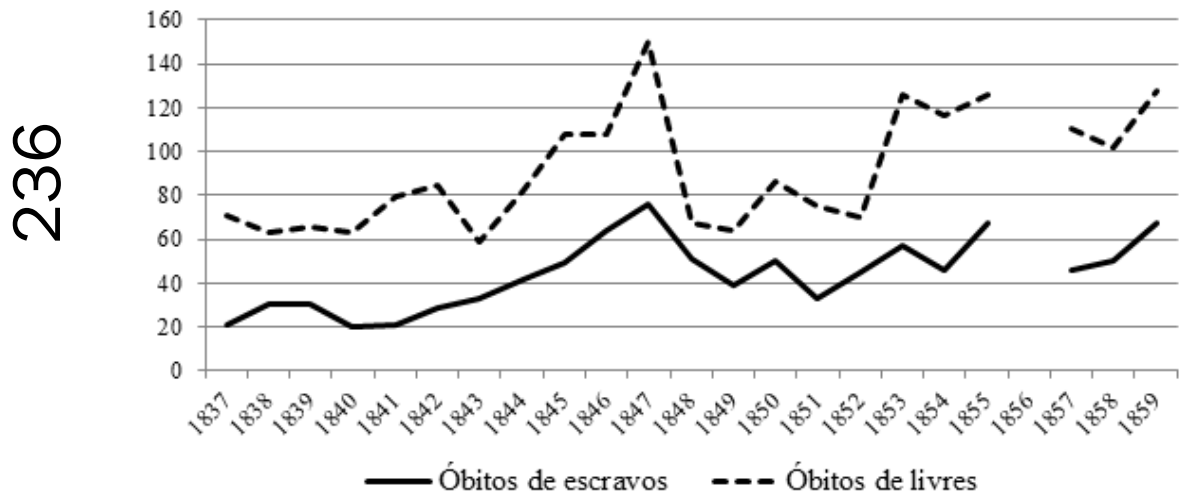

Fonte: Livros de registros de óbito de Limeira (1833-1860).

Se pudermos considerar mais ou menos constantes as taxas de mortalidade, na população, e de sub-registro, na documentação, então ficaremos com a imagem de uma população livre que aproximadamente dobrou em cerca de 20 anos, ao passo que o contingente escravo pode ter crescido mais que isso. $\mathrm{O}$ confronto da lista nominativa de habitantes dos anos 1840 com as informações fornecidas pela bibliografia a respeito de 1854 permite ressaltar mais um aspecto: 5280 habitantes na lista da década de 1840 e 5045 moradores em 1854, como já foi visto. O crescimento não foi linear. Os próprios óbitos nos deixam com a impressão de que a população executou um movimento em forma de " $N$ ". Os sepultamentos, tanto de livres quanto de escravos, multiplicaram-se rapidamente até 1847, decrescendo a partir de então e ganhando novo ímpeto nos anos 1850, embora sem chegar aos níveis de 1848. É claro que esse movimento de receber migrantes e perder migrantes para outras áreas mais a oeste poderia perfeitamente ter combinado com uma população linearmente crescente. Mas a sucessão muito rápida de avanços e decréscimos no contingente constitui um indício bem seguro, indicando também a violência do processo. À frente serão vistos outros indícios dessa pulsação experimentada por essa espécie 
de boca de sertão no século XIX. Em 1872, haveria em Limeira, segundo o Recenseamento de 1872, 11229 livres e 3064 escravos.

A distribuição por sexo dos escravos adultos mortos mostra, indiretamente, a importância do tráfico de escravos e da presença africana. Faz isso porque o comércio de africanos enchia Limeira de homens e, tanto eles quanto as poucas mulheres traficadas, tendiam a morrer rapidamente (Gráfico 2).

Gráfico 2 - Razão de sexo dos óbitos de escravos com 15 ou mais anos (Limeira, 1837-1859) óbitos de homens X 100 / óbitos de mulheres

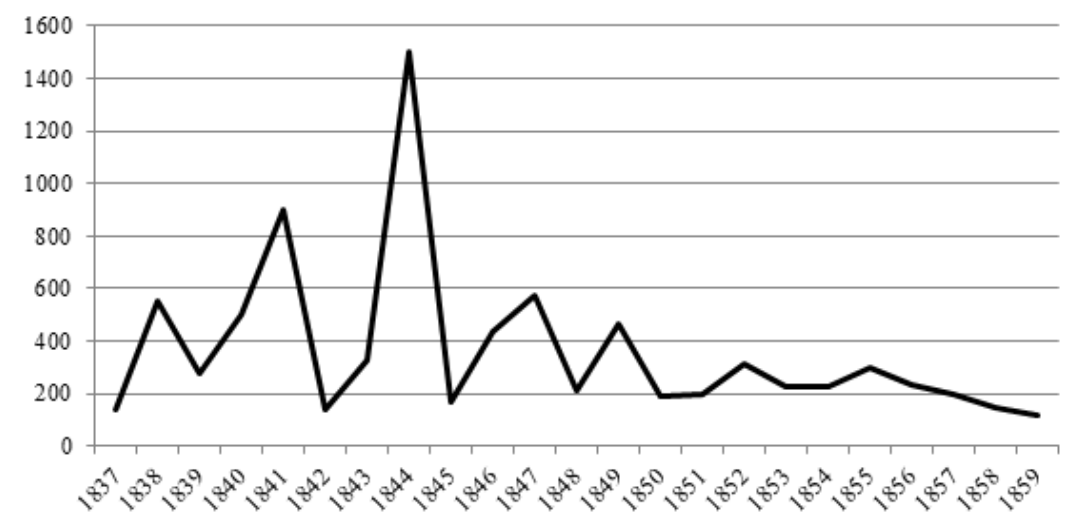

Fonte: Livros de registros de óbito de Limeira (1833-1860).

Em verdade, a curva formada pela evolução da razão de sexo dos óbitos de escravos adultos acaba descrevendo bem demais a trajetória dos proprietários de Limeira pelo tráfico ilegal. De notarse, inicialmente, que raramente a presença masculina nos óbitos de adultos descia abaixo de dois homens para cada mulher, indicador de um recurso quase desesperado à compra de africanos. Em segundo lugar, observe-se o caráter acidentado da curva, que, se não tiver sido aleatório, poderá mostrar uma característica fundamental do comércio ilegal de almas, qual seja, a instabilidade introduzida nas condições de negociação pela pressão política e institucional, 
mesmo que esta última não tenha sido capaz de eliminar a atividade e nem de impedir que ela ganhasse um ímpeto importante no final dos anos 1840. E, de fato, as oscilações não eram aleatórias, pelo menos não de acordo com o que se sabe por outras fontes a respeito da atividade ilícita. Elas apontam para o crescimento dessa atividade na segunda metade dos anos 1830, assim como para o impacto negativo sobre ela, no início dos anos 1840, da superação de parte da instabilidade legada pelo período regencial, viabilizando a repressão. Indicam o acirramento da pressão inglesa, levando a queda ingente ao redor de 1845 , mas também para sua retomada após essa data, compondo um último assomo de crueldade, assim como para a peculiaridade dos últimos anos da década de 1840, momento de retração no tráfico antes mesmo da efetividade da proibição, provavelmente em virtude de mecanismos derivados da política monetária contracionista relacionada à fixação da paridade do mil-réis realizada em 1846 (PELÁEZ; SUZIGAN, 1976, p. 32-34). Por fim, deixam claro o banimento mesmo do tráfico de escravos, em 1850, que só mostrou efeitos em Limeira uns quatro anos após os últimos desembarques (já que cada desembarque de africanos se refletia nos óbitos por uns três anos, graças ao inferno do seasoning). Esses efeitos se manifestaram através de forte decréscimo da razão de sexo dos óbitos.

Essa pulsação da população, e algumas de suas características, aparece também na distribuição por sexo, idade e condição (Quadro 1). É notável a preponderância numérica masculina entre os livres com idades maiores que 30 anos. Já nas faixas etárias mais jovens predominavam as mulheres. Enxergam-se nas idades dos mais velhos as migrações iniciais para o estabelecimento das atividades. É possível, por outro lado, que na distribuição por sexos entre os livres em idade plenamente adulta se reflita já a busca por novos sítios, a ocorrência de novo avanços na direção de áreas desocupadas ou em processo de desocupação. 
Quadro 1 - População por sexo, condição e grandes faixas etárias (Limeira, ca. 1845)

\begin{tabular}{|c|c|c|c|c|}
\hline & \multicolumn{2}{|c|}{ Livres } & \multicolumn{2}{c|}{ Escravos } \\
\hline Idades & Masculino & Feminino & Masculino & Feminino \\
\hline 0 a 14 & 869 & 884 & 211 & 214 \\
\hline 15 a 29 & 409 & 540 & 331 & 189 \\
\hline 30 a 49 & 375 & 324 & 336 & 153 \\
\hline 50 a 64 & 129 & 79 & 65 & 14 \\
\hline 65 ou + & 18 & 10 & 14 & - \\
\hline Total & 1800 & 1837 & 957 & 570 \\
\hline
\end{tabular}

Fonte: MAÇOS..., [18--?].

Registros de óbito fornecem sugestão semelhante, embora menos segura. Observaram-se, neste caso, apenas os assentos de falecimento de pessoas livres que fornecessem uma estimativa das idades que tinham no momento fatal. Entre 1834 e 1840, menos de metade dos adultos livres que morriam eram mulheres, e esse predomínio numérico masculino aplicava-se a qualquer faixa etária. As coisas mudaram entre 1841 a 1856. Mulheres continuaram a ser minoritárias entre os que morreram com mais de 44 anos de idade. Mas sobrepujaram os homens entre os mortos com idades entre os 15 e os 44 anos. Ficam retratados no movimento dos óbitos de adultos tanto o período inicial da vila, com imigração expressa pelo predomínio masculino, quanto o período mais próximo ao momento estudado, de preponderância numérica feminina, criando suspeitas de remigração, quase sem "vida normal" no meio do caminho.

A população escrava, acima de tudo, dá margem a que se reflita a respeito de outras características inscritas na conformação 
de uma área de fronteira agroexportadora. Os cativos constituíam três em cada dez habitantes de Limeira nessa época, e a razão de sexo do segmento em seu conjunto (isto é, sem isolar os adultos) alcançava o patamar muito elevado de 168 escravos do sexo masculino para cada cem mulheres. A participação de crianças com até 14 anos na população, de $28 \%$, ultrapassava significativamente o nível verificado em Bananal, em 1829, por José Flávio Motta, de 21\% (MOTTA, J., 1999, p. 130), indo também um pouco além do notado em Piracicaba, em 1828, de 23\% (MAÇOS..., 1828). Por outro lado, havia semelhanças com os patamares verificados em Vassouras, Rio de Janeiro. Segundo Salles, em meados dos anos 1840 as crianças com até 12 anos alcançavam cerca de $24 \%$ do contingente cativo (SALLES, 2008, p. 226), nível idêntico ao de Limeira. Por outro lado, a participação de crianças com até nove anos em Limeira chegava a 18,5\%, patamar bem superior ao do conjunto do Oeste Paulista em 1829, pois de acordo com Luna e Klein essas crianças teriam constituído somente $13 \%$ da população nessa data (LUNA; KLEIN, 2005, p. 178).

De outra parte, a enorme participação africana no conjunto fica bem clara através da alta razão de sexo das faixas etárias a partir dos 15 anos. Talvez isso respondesse ao mercado de café. O de açúcar enfrentava dificuldades ingentes desde aproximadamente 1840 . A oferta de escravos, embora estivesse retomando, por intermédio dos mecanismos da ilegalidade, patamares de forte elevação, fazia-o de modo tumultuado e repleto de fatores de crise, o que pode ser monitorado observando os níveis de preços alcançados nos anos 1840 (LOBO et al., 1971, p. 261).

Defende-se aqui que Limeira era tornada um elo nessa corrente impulsionadora pelas condições institucionais para o acesso à terra. De fato, Nelson Nozoe, seguindo Roberto Smith, referiu-se ao período subsequente ao fim do sistema sesmarial em 1822 como uma fase de "desorganização" (NOZOE, 2008, p. 24-25, p. 326-327). Márcia Motta, discutindo o período estendido de 1822 (fim da concessão de sesmarias) a 1850 (data da Lei de Terras), enfatizou muito os conflitos entre sesmeiros - reconhecidos ou em comisso - e posseiros - pequenos e grandes -, assim como destes entre si (MOTTA, 
M., 1998, p. 40). Esse ímpeto posseiro se manifestava com força na província do Rio de Janeiro, pois, levando em conta seus inventários post mortem, Hebe Mattos notou ter aumentado muito ao redor da metade do século a proporção de proprietários de terrenos em todas as camadas sociais retratadas nos documentos, contrastando vivamente com uma imensa maioria de inventariados destituídos de acesso à terra em 1820 (MATOS, H., 1995, p. 91). Adota-se aqui perspectiva semelhante à de João Fragoso, que enfatiza a "[...] rápida formação da agricultura cafeeira numa região de fronteira [...] numa época marcada, a nível internacional, pela fase B de um ciclo Kondratieff (1815-1850)" (FRAGOSO, 1990, p. 134, p. 138). Sugere enquadrar o processo na "[...] reiteração de criação de sistemas agrários escravistasmercantis em áreas de fronteiras, enquanto fenômeno vinculado à reprodução da sociedade escravista" (FRAGOSO, 1990, p. 134, p. 138). Assim, entre as respostas à crise e as quebras institucionais que abriam caminho à expansão territorial, criavam-se condições ímpares para uma movimentação feroz e quase ininterrupta.

Sergio Milliet referiu-se, quanto ao período 1836-1854, a um avanço simultâneo da ocupação humana - e, em ritmo nem sempre idêntico, do café - nas áreas que depois, em função das estradas de ferro, seriam chamadas de Mogiana e Paulista (a esta pertencia Limeira). Mogiana e Paulista teriam sido "[...] sertão para o qual se abriam as portas de Campinas, Bragança, Piracicaba”. Mostrou que as duas populações cresceram em paralelo, mas também que a produção cafeeira da segunda aumentou mais - e mais precocemente - que a da primeira região (MILLIET, 1938, p. 59).

Padrões inscritos na posse de escravos são cruciais para situar Limeira no interior da trajetória da fronteira paulista. Isso constitui o assunto da próxima seção.

\section{Estrutura de posse de escravos}

Como já se suspeita em relação a esse momento mais avançado do século XIX, a posse de escravos era muito concentrada na Limeira dos anos 1840 (Quadro 2). Isso também deve ter resultado do impacto 
da primeira proibição do tráfico sobre as condições brasileiras. Mesmo não tendo posto fim ao comércio de almas, essa mudança institucional, pela via dos preços e da irregularidade, que tornou as condições de acesso a cativos reféns da instabilidade política, fez com que os livres começassem a se ver mais excluídos do que nunca do asqueroso privilégio de possuir escravos. A própria camada dos proprietários de cativos se encontrava fortemente hierarquizada, e quanto a isso note-se que o desvio padrão (fogos com escravos) era o dobro da média, denunciando fortíssimas discrepâncias para cima causadas pela presença das maiores posses. Os índices de Gini não diferem dos calculados com a gigantesca amostra montada por Luna e Klein para o Oeste Paulista de 1829: os do Oeste de Luna e Klein ficaram em 0,64 para os escravistas e em 0,90 para todos os fogos; os de Limeira, em 0,67 e 0,89, respectivamente. A posse mediana no Oeste de 1829 foi de 4, assim como a observada em Limeira por volta de 1845. Mas a média, que em 1829 era de 11 na grande região, mostrou-se quase 13 em Limeira (LUNA; KLEIN, 2005, p. 161).

\section{Quadro 2 - Indicadores sobre a posse de escravos em Limeira (ca. 1845)}

\begin{tabular}{|c|c|}
\hline Indicador & Valor \\
\hline Tamanho médio das escravarias (todos os fogos) & 2,0 \\
\hline Desvio padrão (todos os fogos) & 11,1 \\
\hline Índice de Gini (todos os fogos) & 0,892 \\
\hline Participação dos fogos com escravos no total de fogos & $15,3 \%$ \\
\hline Tamanho médio das escravarias (fogos com escravos) & 12,9 \\
\hline Tamanho mediano das escravarias (fogos com escravos) & 4 \\
\hline Desvio padrão (fogos com escravos) & 25,8 \\
\hline Índice de Gini (fogos com escravos) & 0,666 \\
\hline
\end{tabular}

Fonte: MAÇOS..., [18--?].

Pode-se acrescentar que a participação dos domicílios escravistas no total dos fogos em Limeira (15\%) era substancialmente menor 
que na Piracicaba de uns vinte anos antes, onde ela fora de 26\%, e note-se que Limeira resultou de desmembramento de Constituição/ Piracicaba (MAÇOS..., [18--?]). Um processo de exacerbação das disparidades entre as pessoas livres esteve efetivamente em curso durante as décadas de 1830 e 1840 . Relacionar a posse de escravos com o transcurso da vida das pessoas corrobora essa imagem de novos patamares da desigualdade entre os livres (Quadro 3).

Dados coletados em cross section impõem leitura comedida das curvas que se entreveem nos dados do Quadro 3. Mas, se deixarmos de lado o escravista de menos de 20 anos de idade e o acidente da faixa etária dos 50 aos 59 anos, observaremos que média e mediana têm desempenhos invertidos. A média tendia a crescer e no fim da vida caía. A mediana, a recuar um pouco na maturidade bem demarcada, para após isso crescer bastante (a partir dos sessenta anos de idade). Supondo que medianas muito inferiores a médias indicam desvios importantes para cima, pode-se dizer que a desigualdade entre os proprietários se afirmava juntamente com a plena realização de suas carreiras, recuando em seguida. A disparidade extrema parece ter sido o horizonte dos homens feitos e maduros, aquilo que se esperava da vida normal. $\mathrm{O}$ transcurso das carreiras como que decanta padrões esperados. Tratava-se, pode-se supor, da vida como ela deveria ser: intensamente desigual (FRAGOSO; FLORENTINO, 2001, cap. 2 e 3).

\section{Quadro 3 - Posse de escravos e ciclo de vida (Limeira, ca. 1845)}

\begin{tabular}{|c|c|c|c|}
\hline $\begin{array}{c}\text { Faixas etárias } \\
\text { dos aparentes } \\
\text { chefes de fogo }\end{array}$ & $\begin{array}{c}\text { № médio de } \\
\text { escravos - todos } \\
\text { os chefes de } \\
\text { fogo }\end{array}$ & $\begin{array}{c}\text { № médio de } \\
\text { escravos - só } \\
\text { escravistas }\end{array}$ & $\begin{array}{c}\text { № mediano de } \\
\text { escravos - só } \\
\text { escravistas }\end{array}$ \\
\hline $10-9$ & 1,8 & $*$ & $*$ \\
\hline $20-9$ & 0,8 & 10,7 & 4 \\
\hline $30-9$ & 1,6 & 10,2 & 4 \\
\hline $40-9$ & 2,5 & 14,4 & 3 \\
\hline
\end{tabular}


Comunidade e tensão na fronteira agrária paulista...

\begin{tabular}{|c|c|c|c|}
\hline $50-9$ & 1,4 & 6,5 & 3 \\
\hline $60-9$ & 9,0 & 35,9 & 8 \\
\hline 70 ou + & 1,1 & 6,5 & 7 \\
\hline
\end{tabular}

Havia apenas um proprietário nessa situação, com 35 escravos.

Obs.: Neste caso, a desigualdade ficou um pouco subestimada por ter sido necessário suprimir os fogos dos grandes proprietários absenteístas (não se conhecem suas idades).

Fonte: MAÇOS..., [18--?].

Assim, nessa fronteira manteve-se, e pode mesmo ter-se aprofundado, a tendência à construção de situações de extrema desigualdade. Isso conduz a examinar se tendências mais excludentes se manifestaram, e, para tratar dessa outra questão, indaga-se a respeito do grau de abertura ou fechamento dessa fronteira para os pobres de maciça presença na sociedade.

\section{Fronteira também para pobres?}

Essa fronteira agrária já nasceu voltada para a agroexportação. Assim, a presença de pobres autônomos nela era comparativamente pequena. Assim, os fogos chefiados por descendentes livres de escravos constituíam 11,5\% do total, ao passo que em Piracicaba, em 1828, haviam composto $21,4 \%$ do conjunto (MAÇOS..., [18--?]). Mas devese ainda levar em conta a combinação de frente pioneira e frente de expansão continua a ser necessária (MARTINS, 1996). Antes do período estudado, figura chave em Limeira monitorava perfeitamente bem as migrações de depauperados para as fronteiras. Nicolau Pereira de Campos Vergueiro referiu-se em 1822 à "[...] grande liberdade de que goza a classe pobre ou de pouca fortuna, tendo grande facilidade, que até parece converter-se em propensão, de mudar de domicílio na certeza de encontrar em qualquer outra província, abundantes meios de subsistência” (VERGUEIRO, 1979, p. 53). Maria Coleta F. A. de Oliveira, por exemplo, defendeu que até mesmo no final do século, não obstante a oferta elástica de força de trabalho propiciada pela imigração, 
[...] a população nacional permaneceu integrada à atividade cafeeira através da abertura de novas áreas para o plantio, avançando com sua pequena produção alimentar ao mesmo tempo em que novos cafezais eram formados (OLIVEIRA, M., 1985, p. 10).

Que sirva de exemplo do jogo entre frente pioneira e frente de expansão um tipo muito peculiar de informação presente nas listas de habitantes consultadas, constituído pelos homens nascidos na própria Limeira, segundo prováveis declarações dos mesmos aos recenseadores. Eles teriam consistido nos filhos dos primeiros povoadores locais. Em verdade, os homens desse tipo com trinta anos ou mais de idade eram apenas dois em meados dos anos 1840, o branco Balduíno de Castro e o preto Luís, de 44 anos. Ambos eram então agregados a outros fogos. Balduíno, ao de um "telheiro" viúvo, ao passo que Luís o era ao de um pequeno proprietário de escravos (dono de 4 cativos). Os dois cabeças de domicílio eram migrantes, o telheiro de Bragança e o lavrador escravista, de Mogi Mirim. Posições conquistadas na fronteira pelos pais e mães dos dois limeirenses não duraram muito frente ao avanço de novos povoadores. É possível que outros povoadores iniciais tivessem migrado mais para o oeste. Entre os chefes de fogo nascidos em Limeira, o mais velho tinha 25 anos de idade.

Variáveis aproximativas para o estudo da autonomia da pobreza estão no Quadro 4, que associa às idades de brancos e descendentes livres de escravos as posições ocupadas pelos limeirenses nos domicílios. Avaliações transversais não são tão adequadas quanto as longitudinais para compreender trajetos (COSTA, 2011), mas elas fornecem pistas importantes, e portanto se deixa aqui caminho aberto a que elas informem sobre os graus segundo os quais se combinaram, dentro do processo de ocupação de Limeira, as lógicas da frente pioneira e da frente de expansão. Assim, esse instrumento meio bruto, mas útil, transforma a posição observada das pessoas na provável estrutura domiciliar em informação a respeito das chances de estabelecerem-se autonomamente e de permanecerem nessa condição (Quadro 4). 
Os problemas normais dos estudos em cross section intervêm. Por exemplo, o pessoal com 30 a 39 anos na lista passou pela faixa etária de menos de vinte anos na expansiva década de Independência, enquanto a vida com menos de vinte do pessoal com 20 a 29 se deu nos anos 1830, quando o impacto da recessão atlântica já se fazia sentir no Brasil. Além disso, diversas outras questões tornam muito bruta a imagem resultante dessa utilização dos dados: encabeçar domicílio nem sempre significava autonomia no sentido econômico, e muito menos no político (BARICKMAN, 2003); deixar de ser computado como filho nem sempre significava casar-se; ser posicionado como co-residente nem sempre implicava subordinação, pois a co-residência podia significar ajuda mútua ou preservação de posição social estabelecida por acordo entre parentes; as chances ou a propensão de jovens para estabelecerem-se eram afetadas de várias maneiras pelo fato de se ter ou não tratado de domicílios escravistas, o que não é capturado pelo procedimento para evitar números pequenos demais (mais ou menos o mesmo se aplica ao modo como se procedeu em relação a co-residentes).

\section{Quadro 4 - Brancos e descendentes livres de escravos -} distribuição (\%) pelas posições na estrutura dos domicílios conforme as faixas etárias (Limeira, ca. 1845)

\begin{tabular}{|c|c|c|c|c|c|c|}
\hline \multicolumn{7}{|c|}{ Descendentes livres de escravos } \\
\hline & $\begin{array}{c}0 \text { a 9 } \\
\text { anos }\end{array}$ & $\begin{array}{c}10 \text { a } 19 \\
\text { anos }\end{array}$ & $\begin{array}{c}20 \text { a } 29 \\
\text { anos }\end{array}$ & $\begin{array}{c}30 \text { a } 49 \\
\text { anos }\end{array}$ & $\begin{array}{c}50 \text { a } 69 \\
\text { anos }\end{array}$ & $\begin{array}{c}>=70 \\
\text { anos }\end{array}$ \\
\hline $\begin{array}{c}\text { Chefes c/ } \\
\text { escravos } \\
\text { ou cônjuges }\end{array}$ & - & - & - & 7,3 & 4,5 & - \\
\hline $\begin{array}{c}\text { Chefes s/ } \\
\text { escravos } \\
\text { ou cônjuges }\end{array}$ & - & 16,9 & 73,0 & 82,4 & 86,4 & 100,0 \\
\hline
\end{tabular}


Carlos Alberto Medeiros Lima

\begin{tabular}{|c|c|c|c|c|c|c|}
\hline $\begin{array}{l}\text { Filhos com } \\
\text { pais ou mães }\end{array}$ & 90,1 & 62,6 & 14,3 & 1,5 & - & - \\
\hline Agregados & 9,9 & 20,5 & 12,7 & 8,8 & 9,1 & - \\
\hline Total (abs.) & 91 & 83 & 63 & 68 & 22 & 1 \\
\hline \multicolumn{7}{|c|}{ Brancos } \\
\hline & $\begin{array}{l}0 \text { a } 9 \\
\text { anos }\end{array}$ & $\begin{array}{c}10 \text { a } 19 \\
\text { anos }\end{array}$ & $\begin{array}{c}20 \text { a } 29 \\
\text { anos }\end{array}$ & $\begin{array}{c}30 \text { a } 49 \\
\text { anos }\end{array}$ & $\begin{array}{c}50 \text { a } 69 \\
\text { anos }\end{array}$ & $\begin{array}{l}>=70 \\
\text { anos }\end{array}$ \\
\hline $\begin{array}{c}\text { Chefes c/ } \\
\text { escravos } \\
\text { ou cônjuges }\end{array}$ & - & 1,4 & 7,7 & 16,8 & 21,1 & 10,5 \\
\hline $\begin{array}{c}\text { Chefes s/ } \\
\text { escravos } \\
\text { ou cônjuges }\end{array}$ & - & 8,3 & 64,9 & 72,6 & 64,4 & 63,2 \\
\hline $\begin{array}{c}\text { Filhos com } \\
\text { pais } \\
\text { ou mães }\end{array}$ & 93,9 & 79,2 & 17,8 & 1,4 & - & - \\
\hline Agregados & 6,1 & 11,0 & 9,6 & 9,2 & 14,4 & 26,3 \\
\hline Total (abs.) & 1151 & 770 & 562 & 632 & 194 & 19 \\
\hline
\end{tabular}

Fonte: MAÇOS..., [18--?].

As chances de alcançar a autonomia - e a precocidade em chegar à condição de chefe de fogo indiciava que elas eram grandes - indicam a receptividade da fronteira ao campesinato migrante, conforme a expressão de Hebe Mattos (MATTOS, H., 2001). Os homens e 
mulheres livres que descendiam de escravos distanciavam-se mais precocemente que brancos das casas onde haviam nascido, fosse para se agregarem a outros fogos, fosse para tornarem-se chefes de fogo. Brancos raramente se agregavam na infância e logo em seguida; residir em fogo não chefiado por eles era algo mais encontradiço na velhice. Entre descendentes de libertos, a agregação se dirigia especialmente para crianças e jovens. Isso tudo não deve fazer esquecer terem sido efetivamente muito poucos os agregados em Limeira.

Quanto à saída do fogo paterno ou materno por parte dos descendentes livres de escravos, pode-se dizer o mesmo com outras palavras chamando a atenção para as chances de chefiar domicílios entre os que tinham idades menores que vinte anos. Os jovens chefes de fogo descendentes de libertos participavam desse grupo etário em grau um tanto mais elevado que seus companheiros de idade brancos. Similarmente, parecem ter-se casado mais cedo que os jovens brancos.

As chances de atingir a condição de senhor de escravo eram afetadas pelas etapas da vida. Mas, para brancos, isso evidentemente significava que as chances eram bem maiores, que essas oportunidades apareciam mais cedo na vida, e que elas se reduziam apenas levemente na velhice. É óbvio que, para descendentes livres de escravos, as chances apareciam mais tarde, eram sempre menores e desapareciam na velhice. É simplesmente desnecessário escrever que eventuais proprietários negros ou pardos de escravos possuíam escravarias ínfimas em comparação com as pertencentes a brancos.

Logo acima ficou escrito que as chances de aparecer como proprietário de escravos reduziam-se nas idades mais avançadas até mesmo no caso dos brancos. Isso combina com o avançado acima quanto ao tamanho das posses e com as análises sobre ciclo de vida e posse de escravos (COSTA, 2011; MARCONDES, 1998, p. 143-157; LUNA; KLEIN, 2005, p. 149). Aqui, nota-se fenômeno semelhante ao observar se os brancos mantinham-se ou não proprietários de cativos. Dos 30 aos 49 anos, um sexto deles chefiava fogos com escravos. Dos 50 aos 69 anos, entre um quinto e um quarto. Mas a proporção se reduzia a um décimo após ultrapassarem os setenta anos de idade. 
Isso também tem importância no sentido de sugerir a prevalência de mecanismos de transmissão de bens em vida, ou outras estratégias de reprodução de casas senhoriais. Chama a atenção o fato de isso ocorrer em período avançado do século XIX. Pede cuidado também a circunstância de tal coisa ter-se passado em um ambiente onde os recursos não eram escassos, pelo menos não a terra (tratava-se da fronteira). Isso leva a discutir a prevalência do senhorialismo.

\section{Mundo senhorial tardio}

A referência a ele, além de passar pela desigualdade, necessita do tratamento de formas de organização social. Nesse sentido, é acessível, com a documentação utilizada, verificar os tamanhos dos domicílios tendo em vista apenas seus habitantes livres. Excluem-se os escravos em virtude desse foco na organização social: a capacidade de manter livres sob seu controle aponta para um modo de dominação, para a posição que senhores se autoatribuíam na vida social (Quadro 5).

\section{Quadro 5 - Tamanho médio do fogo}

(somente habitantes livres) conforme cor, sexo e idade do cabeça (Limeira, ca. 1845)

\begin{tabular}{|c|c|c|c|c|c|c|}
\hline $\begin{array}{c}\text { Características } \\
\text { do cabeça }\end{array}$ & $\begin{array}{c}\mathbf{1 0} \\
\text { a 19 } \\
\text { anos }\end{array}$ & $\begin{array}{c}\mathbf{2 0} \\
\text { a } 29 \\
\text { anos }\end{array}$ & $\begin{array}{c}\mathbf{3 0} \\
\text { a 39 } \\
\text { anos }\end{array}$ & $\begin{array}{c}40 \\
\text { a 49 } \\
\text { anos }\end{array}$ & $\begin{array}{c}50 \\
\text { a 69 } \\
\text { anos }\end{array}$ & $\begin{array}{c}>=70 \\
\text { anos }\end{array}$ \\
\hline $\begin{array}{c}\text { Homens brancos } \\
\text { Média }\end{array}$ & 2,4 & 3,9 & 4,8 & 5,8 & 5,8 & 3,6 \\
\hline № casos & 13 & 163 & 200 & 125 & 118 & 10 \\
\hline $\begin{array}{c}\text { Mulheres brancas } \\
\text { média }\end{array}$ & - & 2,8 & 4,5 & 3,0 & 3,6 & - \\
\hline № casos & 1 & 10 & 13 & 27 & 18 & 1 \\
\hline $\begin{array}{c}\text { Descendentes } \\
\text { homens de } \\
\text { escravos } \\
\text { média }\end{array}$ & - & 2,9 & 5,8 & 5,0 & 4,2 & - \\
\hline
\end{tabular}


Comunidade e tensão na fronteira agrária paulista...

\begin{tabular}{|c|c|c|c|c|c|c|}
\hline No casos & 1 & 18 & 17 & 12 & 12 & - \\
\hline $\begin{array}{c}\text { Mulheres des- } \\
\text { cendentes de } \\
\text { escravos } \\
\text { média }\end{array}$ & 1,3 & 2,7 & 2,5 & 2,0 & 3,3 & - \\
\hline № casos & 4 & 7 & 8 & 8 & 6 & 1 \\
\hline
\end{tabular}

Fonte: MAÇOS..., [18--?].

Antes de comentar os resultados, é preciso levar em consideração o fato de terem sido poucos os agregados em toda a província (MARCÍLIO, 2000, p. 98-99; SAMARA, 1977, p. 13-121). Isso significa ter sido a quantidade de filhos aquilo que fazia variar de modo mais pronunciado o tamanho de cada fogo (deve ser recordado que nesse momento só se levam em conta as pessoas livres). Se observarmos os dados referentes a domicílios chefiados por homens brancos e por descendentes de escravos, no entanto, veremos que a idade da saída desses filhos da casa paterna também interferia, e era diferenciada conforme a cor. Os fogos dos que tinham ancestrais cativos chegavam ao auge de sua composição quando o cabeça estava na casa dos trinta anos (ele mesmo se casara cedo, provavelmente), e começavam a esvaziar-se com alguma velocidade logo em seguida.

Os domicílios chefiados por homens brancos eram mais patriarcais. Demoravam um pouco mais para crescerem de tamanho, certamente porque essas pessoas deviam casar-se mais tardiamente. Mas permaneciam no auge por muito tempo, aparentemente por cerca de trinta longos anos. Em parte, as razões eram as mesmas: filhos demoravam mais para deixar a casa paterna. Como não era por falta de terra e de fronteira expansiva que isso ocorria, encontramos aqui outra questão atinente às estratégias de reprodução de casas senhoriais, com tudo acontecendo na fronteira e em plena década de 1840 .

O esvaziamento rápido dos fogos de descendentes livres de escravos mostra também outra coisa. Indica que o movimento para a fronteira pode ter sido ainda mais intenso nesse grupo social.

Tendo visto até agora o aumento das disparidades sociais e a sobrevivência parcial de práticas senhoriais, é importante verificar, novamente de modo indireto, se isso se manifestava na abertura ou 
fechamento dos grupos sociais uns em relação aos outros. Uma breve entrada no problema das alianças matrimoniais ajudará a percebê-lo.

Fontes como aquelas aqui usadas não dão muitas opções para o exame de atitudes e relações entre grupos, mas permitem a elaboração de pistas. As uniões matrimoniais descritas sumariamente nessas fontes facultam relances a respeito das relações entre brancos, pardos e negros no período, o que se observa levando em conta as cores atribuídas aos cônjuges. Isso é muito sumário e frustrante, pois muita exogamia, do ponto de vista social e mesmo étnico, fica escondida no registro, para citar um exemplo, de que um homem branco era casado com uma mulher também branca. Inversamente, no entanto, o registro da união de uma mulher parda com um homem branco não deixa dúvidas acerca de ter ocorrido exogamia. Assim, examinar o recenseamento feito por volta de 1845 permite elaborar um indicador bruto, mas útil: examina-se a presença proporcional da exogamia visível, o que se torna um pouco mais eloquente quando ela é confrontada com a vigente em outros locais e épocas.

Em Limeira, entre 582 uniões entre pessoas que não fossem escravas, apenas três eram visivelmente exogâmicas (dois brancos casados com pardas e um africano unido a uma moça designada como "preta"). Essa desinamadora taxa de meio por cento de exogamia visível pode ser comparada. Ela era mais característica da fronteira paulista que produto do período pós-1830, o que se afirma aqui levando em conta o caso de Constituição (depois Piracicaba), em 1828. De 894 uniões entre não-escravos, houve apenas duas entre brancos e mulheres pardas ou mulatas, assim como outras duas entre homens designados como negros e mulheres pardas ou mulatas. A fronteira agroexportadora fazia decair, aparentemente, a importância da prática dos casamentos entre pessoas pertencentes a grupos diferentes de cor/condição. Para comparar, idêntico procedimento encaminhado quanto à vila de Castro, em 1835, apontou que quase cinco por cento dos casamentos uniam pessoas de grupos diferentes, indicando proporção nada menos que dez vezes maior (LIMA, 2005).

As parcas informações reunidas não indicam maior fechamento dos grupos. Tratava-se de tendência própria do tipo específico de fronteira de que se tratava, pois ali as coisas já eram assim desde 
antes de 1830. Por outro lado, é incontornável que o intervalo aberto neste último ano acirrou a movimentação na direção dessas fronteiras do Oeste Paulista. Assim, mesmo que nada houvesse no período que tendesse a afastar grupos sociais, não se pode deixar de lado o fato de que o tipo de área mais crescente no período era exatamente a espécie de ambiente social onde esse afastamento fazia muito sentido. É preciso explorar a possibilidade de que isso afetasse as relações com escravos, tema da próxima seção.

\section{Família escrava}

Sabemos com segurança desde o trabalho de Luna e Klein (2005, p. 185) que, no Oeste paulista, duas características marcavam as populações escravas: a participação de africanos era a maior da província, mas a presença relativa das mulheres cativas casadas ou viúvas também era, e disparado, a maior de São Paulo. Como Slenes (1999, p. 107), Motta (1999, p. 281), Florentino e Góes (1997, p. 95) notaram há tempos, tanto não é verdade que a agroexportação de alguma forma impedia a família escrava, que a presença desta se tornava mais abrangente e mais perceptível nas maiores escravarias.

Analogamente, era muito alta a participação de mulheres na população crioula de Limeira. Não é só porque o fenômeno é semelhante ao verificado na população livre que se pode entrever o dedo senhorial na questão (ver o Quadro 6). Parece ter havido confluência entre senhores e escravos no tocante à formação de famílias. Isso se nota por intermédio do fato de que, ao lado de enorme participação africana - e portanto masculina - na população, os escravos nascidos no Brasil levados para Limeira eram majoritariamente do sexo feminino. A participação escrava nisso certamente não ultrapassava a pressão política, já que eles não controlavam as migrações que realizavam, e certamente se tratava de algum tipo de estratégia senhorial, ou então de algo que não conflitava com essas estratégias.

A razão de sexo entre escravos crioulos era, como se vê pelo Quadro 6, de 90 até os 14 anos de idade, e de 82 dos 15 aos 29 anos 
e de 77 daí até os 49 anos de idade. Essa composição foi certamente ajustada pelos senhores, misturando os registros da desagregação por migrações e do impulso na direção da formação comunitária.

\section{Quadro 6 - Escravos crioulos em Limeira (ca. 1845) segundo sexo e idade}

\begin{tabular}{|c|c|c|}
\hline Idades & Masculino & Feminino \\
\hline 0 a 14 & 184 & 204 \\
\hline 15 a 29 & 90 & 110 \\
\hline 30 a 49 & 33 & 43 \\
\hline 50 a 64 & 5 & 2 \\
\hline 65 ou + & 3 & - \\
\hline Total & 315 & 359 \\
\hline
\end{tabular}

Fonte: MAÇOS..., [18--?].

Aquilata-se essa mistura de registros observando-se o modo como as unidades açucareiras podem ser detectadas na fonte. Não há referência a quantidades produzidas, ou a seu valor, mas sim dados sobre a presença de feitores e administradores, além da classificação de senhores de engenho como "engenheiros". Uma coisa que chama a atenção ao olhar-se para os dados desses engenhos é a presença de feitores e administradores que apareciam como se fossem os cabeças dos fogos dos engenhos nos quais atuavam. Isso se passava em três dos dez engenhos com mais de 40 escravos ou mais. Inversamente, mas apontando para a mesma realidade de absenteísmo, quase um terço dos 27 "engenheiros" apareciam chefiando fogos com menos de dez cativos, o que quase certamente significa que não residiam em seus engenhos. Talvez o absenteísmo abarcasse mais de um quarto dos engenhos. Devemse mencionar igualmente questões jurisdicionais que acabavam por situar fazendas enormes ao mesmo tempo em Rio Claro e em Limeira, tendo este sido o caso de dona Gertrudes Galvão de Oliveira Lacerda e de Nicolau Pereira de Campos Vergueiro, de modo que, absenteístas ou não estes últimos, seu domicílio podia 
ser lançado em qualquer um dos dois lugares, aproximando-se de alguma forma de absenteísmo.

Isso oportuniza abordar um caso para relacionar Limeira à reputação do absenteísmo com feitores. A maior escravaria local, com duzentos escravos, certamente um fogo de absenteísta, era provavelmente - conforme se entrevê pelo cruzamento dos nomes dos escravos na lista com aqueles presentes em registros de óbitos e de batismo - a fazenda do Morro Azul, de dona Gertrudes Galvão. Nada a particularizava quanto ao tratamento, segundo as sumárias descrições contidas na lista de habitantes. A proporção de crianças escravas (0 a 14 anos), por exemplo, era idêntica à do conjunto de Limeira, isto é, de 28\%. Nos registros de batismo, a taxa de ilegitimidade dos escravos dessa unidade limitava-se a 3\%, muitíssimo menor que a da população escrava de Limeira em seu conjunto (sobre isso, vide as fontes do Quadro 7). A julgar por essas informações, unidades de absenteístas com feitores na fronteira Oeste de São Paulo não eram necessariamente aquelas de relações mais duras, como se escreve frequentemente em relação ao Caribe (GENOVESE, 1979, p. 41-43).

Além disso, já se notou que as taxas de ilegitimidade em áreas açucareiras, inclusive as da fronteira paulista (caso de Limeira), eram muito baixas em comparação com outras regiões da província (Quadro 7).

\section{Quadro 7 - Taxas de ilegitimidade nos batismos de crianças escravas em paróquias das províncias de São Paulo e do Paraná (1812-1855)}

\begin{tabular}{|c|c|c|c|c|}
\hline Local & Período & Característica & No de casos & $\begin{array}{c}\text { \% só nome } \\
\text { da mãe }\end{array}$ \\
\hline & $1817-30$ & Café & 460 & 42 \\
\hline & $1831-40$ & Café & 696 & 53 \\
\hline Bananal & $1841-52$ & Café & 1540 & 58 \\
\hline & $1826-36$ & Café & 667 & 37 \\
\hline Areias & 1845 & Café & 58 & 36 \\
\hline & $1833-40$ & Café & 291 & 36 \\
\hline
\end{tabular}


Carlos Alberto Medeiros Lima

\begin{tabular}{|c|c|c|c|c|}
\hline Silveiras & $1841-54$ & Café & 664 & 42 \\
\hline \multirow[t]{2}{*}{ Queluz } & $1845-53$ & Café & 461 & 33 \\
\hline & $1830-40$ & Alimentos & 691 & 55 \\
\hline Cunha & $1841-52$ & Alimentos & 607 & 77 \\
\hline \multirow[t]{2}{*}{$\begin{array}{l}\text { Freg. de } \\
\text { Lorena }\end{array}$} & 1847 & Alimentos & 59 & 58 \\
\hline & $1831-40$ & Cana & 327 & 21 \\
\hline \multirow[t]{2}{*}{ Rio Claro } & $1841-51$ & Cana e café & 611 & 29 \\
\hline & $1831-40$ & Cana & 345 & 15 \\
\hline \multirow[t]{2}{*}{ Limeira } & $1841-53$ & Cana e café & 820 & 22 \\
\hline & $1831-40$ & Cana & 933 & 14 \\
\hline \multirow[t]{2}{*}{ Piracicaba } & $1841-51$ & Cana e café & 659 & 21 \\
\hline & $1832-40$ & Cana & 160 & 22 \\
\hline \multirow[t]{3}{*}{$\begin{array}{c}\text { Santa } \\
\text { Bárbara }\end{array}$} & $1841-50$ & Cana & 215 & 25 \\
\hline & $1821-30$ & Cana & 216 & 18 \\
\hline & $1831-38$ & Cana & 512 & 11 \\
\hline \multirow[t]{3}{*}{ Capivari } & $1839-50$ & Cana & 1105 & 20 \\
\hline & $1812-30$ & Criação/tropas & 374 & 70 \\
\hline & $1831-40$ & Criação/tropas & 196 & 67 \\
\hline \multirow[t]{2}{*}{ Palmeira } & $1841-55$ & Criação/tropas & 327 & 71 \\
\hline & $1831-40$ & $\begin{array}{l}\text { Criação/tropas, } \\
\text { alimentos }\end{array}$ & 526 & 52 \\
\hline \multirow[t]{2}{*}{ Castro } & $1841-51$ & $\begin{array}{c}\text { Criação/tropas, } \\
\text { alimentos }\end{array}$ & 618 & 59 \\
\hline & $1832-40$ & Alimentos & 87 & 78 \\
\hline $\begin{array}{c}\text { Campo } \\
\text { Largo }\end{array}$ & $1841-55$ & Alimentos & 182 & 94 \\
\hline
\end{tabular}

Fonte: Elaborado pelo autor com base em livros de registro de batismos de paróquias da época. 
Em acréscimo à tendência ao crescimento da ilegitimidade na primeira metade do século XIX, dois tipos de contraste chamam inicialmente a atenção para o conhecido fenômeno segundo o qual a ilegitimidade escrava em uma área era inversamente proporcional ao tamanho médio das escravarias, sendo isso o mesmo que dizer que plantéis maiores consolidavam e legitimavam mais facilmente a família cativa. O primeiro desses contrastes, dentro do Vale do Paraíba, se dá entre as áreas cafeeiras e não cafeeiras, representadas, respectivamente, por Bananal, Areias, Silveiras e Queluz, de um lado, e por Cunha e a freguesia de Lorena, de outro. A ilegitimidade era menor nas áreas cafeeiras. $\mathrm{O}$ outro contraste que chama a atenção de saída é aquele entre as áreas do café, da cana e dos alimentos que compõem o atual estado de São Paulo e aquelas que hoje fazem parte do Paraná. A ilegitimidade era visivelmente maior em Castro, Palmeira e, especialmente, nos plantéis ínfimos de Campo Largo.

Um segundo tipo de contraste opõe as áreas agroexportadoras umas às outras. As do Oeste Paulista, então presas da lavoura canavieira, apresentavam baixíssimas taxas de ilegitimidade, muito menores que as verificadas no Vale do Paraíba cafeeiro. É verdade que as escravarias eram maiores no açúcar que no café, mas a questão não residia exclusivamente nisso. É preciso lembrar, além do mais, a sacarocracia, com seu sentido aristocrático talvez mais voltado para a construção de um mundo comunitário abaixo de si, pois a institucionalização de relações entre escravos podia atuar como um tipo de eufemização dos feitos aristocráticos de açambarcamento. Importante também é levar em consideração a lógica da fronteira, possivelmente difusora de uma espécie de ânsia pela estabilização de relações. A cruel insalubridade da cana, em contraste com a do café, bem menor, também deve ser posta em discussão quanto a isso: muita criança morta pode ter aumentado as simpatias com que todos os grupos sociais enxergavam a maior fecundidade das mulheres escravas casadas, em contraste com as solteiras (SLENES, 1999, cap. 1; FLORENTINO; GÓES, 1997, p. 95; MOTTA, J., 1999, p. 334). 
Observar as grandes escravarias permite monitorar o fato de o tamanho das escravarias não explicar as diferenças entre cana e café. $\mathrm{Na}$ Bananal cafeeira, entre 1824 e 1853, a taxa de ilegitimidade das crianças escravas levadas à pia batismal por Francisco e Manuel de Aguiar Valim, donos de escravarias inegavelmente enormes, ficou em 48\%. Entre as crianças batizadas por Luciano José de Almeida entre 1836 e 1852, essa taxa ficou na casa dos 23\% (vide as fontes citadas no Quadro 7). Os dois casos vêm das grandes escravarias da área cafeeira. $\mathrm{Na}$ lavoura canavieira as coisas eram diferentes. Em Limeira, entre as crianças levadas à pia por Bento Manoel de Barros, apenas 1,7\% eram ilegítimos. Eram ainda mais extremos alguns casos canavieiros, ou do café produzido em ambiente ainda muito marcado pela cana. Quanto aos domínios de Nicolau Pereira de Campos Vergueiro, todas, simplesmente todas as crianças escravas levadas ao sepultamento pelos que tocavam seus negócios tiveram seus óbitos registrados fazendo referência aos nomes de ambos os pais (é melhor tratar o caso dos escravos de Vergueiro com os óbitos, pois ele aparecia estranhamente pouco entre os proprietários de escravos batizados; cf. as fontes do Gráfico 1). Esses óbitos sugerem uma taxa de ilegitimidade escrava equivalente a zero.

\section{Considerações finais}

$\mathrm{Na}$ fronteira agroexportadora, as posições sociais dos livres pareciam estar se afastando, e tal se dava tanto no tocante às sociabilidades, quanto no que diz respeito ao aprofundamento da desigualdade entre eles. Isso condiz com um ambiente de disputas pela terra entre grupos sociais. Exprimiam-se igualmente as vicissitudes do mercado de escravos, mostrando-o já conturbado e instável em função da primeira proibição do tráfico, aumentando preços e contribuindo para tornar menos visível a camada dos pequenos proprietários de cativos. Além disso, alguns mecanismos de mobilidade ascendente pareciam relativamente deprimidos, o que se manifestava na pequena participação no total dos domicílios daqueles chefiados por negros e pardos livres. 
É difícil dizer se a atitude da elite branca em relação aos descendentes livres de escravos constitui algum tipo de informação a respeito de suas políticas quanto aos cativos. Se constituir esse tipo de retrato, então a história, quanto aos escravos, terá sido a de estratégias que os enclausuravam, um pouco como no modelo $\infty$ de "geração da plantation" formulado por Ira Berlin (BERLIN, 1 2006, p. 69-71), que liga isso à história intrínseca do processo de C consolidação da classe senhorial. Aqui, no entanto, os resultados apontam para mudanças institucionais de nível imperial, além do fato de se ter tratado mais de um momento crítico que de um instante de auge daquela classe. Ou então parecer-se-á ao modelo de "administração dos escravos" que Rafael Marquese elaborou para o caso norte-americano e cubano (mas não para o brasileiro) do século XIX (MARQUESE, 2004, p. 343-346). Dale Tomich, por outro lado, dá algum suporte a que se pense nesse processo de mudança nas relações escravistas ao redor da ideia de "segunda escravidão", implicando uma espécie cruel de modernização em função de novo encaixe na economia mundial (TOMICH, 1995, p. 243, por exemplo). Esse conceito ajuda a entender a história desse momento da expansão cafeeira. Auxilia também, parcialmente, a compreender algumas das transformações sofridas pelo açúcar, pois o avanço da lavoura canavieira em São Paulo, além de incorporar áreas novas à produção agrícola para o mercado mundial e de ligar-se a processos que conduziriam à sua substituição pela ênfase no café (também expansivo), teve muita relação com a mudança no mercado do produto, que passou a privilegiar a variedade bruta, mais similar a uma matéria prima. Mas os processos analisados neste estudo tornam-se mais compreensíveis a partir de elementos imperiais, como se escreveu logo acima. O ritmo alucinante da expansão agrária que se abordou aqui deveu pouco ao mercado mundial e muito a questões institucionais ligadas à provisão de terra e à própria presença de uma fronteira expansiva. Do mercado externo, inclusive, vinha um freio - a espécie de derrota sofrida pela produção açucareira brasileira para a cubana.

Importa ressaltar o modo peculiar como a família cativa e a reprodução natural das escravarias se relacionavam com a movimentação geográfica e com a instabilidade ligada ao avanço para 
a fronteira. Viram-se aqui sinais de que a população escrava era marcada por migrações atlânticas (os africanos), por migrações internas (a ocupação dessa fronteira constituída por Limeira) e, quase com certeza, por remigrações. Tudo isso aponta para uma população marcada pela disjunção e pelo desenraizamento, combinados embora ao fato de muitas dessas migrações recomporem comunidades (a família escrava), aparentemente em ligação com a lógica da própria fronteira.

Deu-se, portanto, essa proliferação de sinais invertidos. Persistia de período anterior a forte tendência ao crescimento e à expansão da fronteira agrária, com muita importação de africanos e envolvendo todos os grupos sociais. Persistiam igualmente a desigualdade e as práticas de reiteração de casas senhoriais, apesar das mudanças legais que proibiam vínculos e terminavam por tornar problemáticas práticas informais de reiteração, como a dos dotes.

Alguns elementos novos, no entanto, se associavam a tudo isso. $\mathrm{O}$ crescimento e a expansão passavam a assumir um viés de crise na oferta de fatores e no mercado do açúcar. A expansão agrária ganhava contornos mais conflituosos, por razões institucionais e, logo à frente, por associar-se ao café, que demandava deslocamentos associados à expansão (lembre-se a metáfora da "onda" usada para a cafeicultura, que divergia da metáfora da "mancha" usada para a cana). Além disso, desigualdade estava em processo de exacerbação, provavelmente em associação, agora, com um elemento de distanciamento entre os grupos de livres e destes em relação aos escravos. Essas fronteiras exportadoras pareciam ainda mais tensas que as anteriores. Desigualdade e domínio sempre haviam apartado livres e escravos, mas isso se fizera acompanhar, também tradicionalmente, de ligações no terreno das sociabilidades hierárquicas que formavam o circuito daquelas relações de dominação. Nas tensas circunstâncias do segundo terço do século XIX, no entanto, e além do aprofundamento de várias manifestações da desigualdade constitutiva da vida social, parece ter estado em operação a ruptura de ligações entre as comunidades "incorporadas" vigentes no alto (os robustos domicílios de brancos da fronteira) e embaixo (a família escrava). Por mais que o parentesco cativo estivesse deixando marcas muito fortes na paisagem canavieira paulista, ele executava um movimento 
decrescente, como se viu em relação às taxas de ilegitimidade, e sobretudo à redução da importância das pontes entre grupos sociais. As comunidades incorporadas sobreviviam no alto e se adensavam embaixo, mas há sinais de ter sido decrescente sua comunicação.

\section{COMMUNITY AND TENSION IN SÃO PAULO'S AGRARIAN FRONTIER (LIMEIRA DURING THE 1840S)}

Abstract: The case of Limeira, SP, and that of the province's western frontier along the second quarter of the nineteenth century is useful to understand various tracts of this period. Besides political instability, strong changes occurred in the institutional conditions to establish estates and to acquire and own slaves. Manuscript censuses, as well as death and baptism records are used in order to understand conditions prevalent in this new kind of frontier dedicated to sugar production, with signs of a transition to coffee production. Slave and free population, as well as the slave trade, grew fast, but there were signs that inhabitants were already migrating to areas located further west. An impetus toward community building was also in operation, coupled with the preservation of some aristocratic practices, but increasing inequality depressed mechanisms of social mobility and enhanced the distance between social groups, conducing to a partial withdrawal of hierarchical sociability.

Keywords: Slavery. Agrarian frontier. São Paulo province during the XIXth century. Sugar production. Coffee production.

\section{Referências}

BARICKMAN, B. J. E se a casa-grande não fosse tão grande? Uma freguesia açucareira do Recôncavo Baiano em 1835. Afro-Ásia, Salvador, n. 29-30, p. 79-132, 2003.

BERLIN, Ira. Gerações de cativeiro. Tradução de Julio Castañon. Rio de Janeiro: Record, 2006.

COSTA, Iraci del Nero da. Ciclo de vida e posse de escravos: algumas relações entre cortes transversais e estudos longitudinais. Revista de História Regional, Ponta Grossa, v. 16, n. 2, p. 550-565, 2011.

COSTA, Iraci Del Nero da; NOZOE, Nelson H. Achegas para a qualificação das listas nominativas. Estudos econômicos, São Paulo, v. 21, n. 2, p. 271-284, 1991. 
DEAN, Warren. Rio Claro: um sistema brasileiro de grande lavoura 1820-1920. Rio de Janeiro: Paz e Terra, 1977.

FERLINI, Vera Lúcia Amaral. Terra, trabalho e poder: o mundo dos engenhos no Nordeste colonial. São Paulo: Brasiliense, 1988.

FLORENTINO, Manolo; GÓES, José Roberto. A paz das senzalas: famílias escravas e tráfico atlântico, Rio de Janeiro, c.1790 - c.1850. Rio de Janeiro: Civilização Brasileira, 1997.

FRAGOSO, João. A economia brasileira no século XIX: mais do que uma plantation escravista-exportadora. In: LINHARES, Maria Yedda (Org.). História geral do Brasil. Rio de Janeiro: Campus, 1990. p. 131-176.

FRAGOSO, João; FLORENTINO, Manolo. O arcaísmo como projeto. Rio de Janeiro: Civilização Brasileira, 2001.

GENOVESE, Eugene. O mundo dos senhores de escravos. Rio de Janeiro: Paz e Terra, 1979.

LIMA, Carlos A. M. Hierarquia social, incorporação e estratégias de reprodução no Sul (Paraná, 1730-1835). In: MOURA, A. M. S.; SENA FILHO, N. (Org.). Cidades: relações de poder e cultura urbana. Goiânia: Vieira, 2005. p. 103-132.

LOBO, Eulalia Maria Lahmeyer et al. Evolução dos preços e do padrão de vida no Rio de Janeiro, 1820-1930 - resultados preliminares. Revista Brasileira de Economia, Rio de Janeiro, v. 25, n. 4, p. 235-266, out. 1971. Disponível em: $\langle$ http://bibliotecadigital.fgv.br/ojs/index.php/rbe/article/view/67>. Acesso em: 2 mar. 2017.

LUNA, Francisco Vidal; KLEIN, Herbert S. Evolução da sociedade e economia escravista de São Paulo, de 1750 a 1850. São Paulo: Edusp, 2005.

MAÇOS de população. Piracicaba: Arquivo Público do Estado de São Paulo, [18--?]. MAÇOS de população. Piracicaba: Arquivo Público do Estado de São Paulo, 1828. MARCílIO, Maria Luiza. Crescimento demográfico e evolução agrária paulista, 1700-1896. São Paulo: Hucitec; Edusp, 2000.

MARCONDES, Renato Leite. $A$ arte de acumular na economia cafeeira. Lorena: Stiliano, 1998.

MARQUESE, Rafael. Feitores do corpo, missionários da mente: senhores, letrados e o controle dos escravos nas Américas, 1660-1860. São Paulo: Companhia das Letras, 2004. 
MARTINS, José de Souza. O tempo da fronteira: retorno à controvérsia sobre o tempo histórico da frente de expansão e da frente pioneira. Tempo social, São Paulo, v. 8, n. 1, p. 25-70, 1996.

MATTOS, Hebe. Das Cores do Silêncio. Rio de Janeiro: Arquivo Nacional, 1995. . Campesinato e Escravidão. In: Silva, Francisco Carlos Teixeira da; Mattos, Hebe Maria; Fragoso, João (Org.). Escritos sobre história e educação: homenagem a Maria Yedda Linhares. Rio de Janeiro: Mauad; FAPERJ, 2001. p. 331-350.

MATTOS, Ilmar Rohloff de. O tempo saquarema. São Paulo: Hucitec, 1987. MILLIET, Sergio. Roteiro do café. São Paulo, 1938.

MOTTA, José Flávio. Escravos daqui, dali e de mais além: o tráfico interno de cativos na expansão cafeeira paulista (Areias, Guaratinguetá, Constituição/Piracicaba e Casa Branca, 1861-1887). 2010. (Tese de Livre Docência)-Universidade de São Paulo, São Paulo, 2010.

. Corpos escravos, vontades livres: estrutura da posse de cativos e família escrava em um núcleo cafeeiro (Bananal, 1801-1829). 1990. (Tese)-Universidade de São Paulo, São Paulo, 1990.

MOTTA, Márcia Maria Menendes. Nas fronteiras do poder. Rio de Janeiro: Vício de Leitura/APERJ, 1998.

NOZOE, Nelson. A apropriação de terras rurais na capitania de São Paulo. 2008. (Tese)-Universidade de São Paulo, São Paulo, 2008.

OLIVEIRA, Antonio de Almeida. A lei das execuções. Rio de Janeiro: Garnier, 1887.

OLIVEIRA, Maria Coleta Ferreira Albino de. Questões demográficas no período cafeeiro em São Paulo. Campinas: NEPO/UNICAMP, 1985.

PELÁEZ, Carlos Manuel; SUZIGAN, Wilson. História monetária do Brasil. Rio de Janeiro: IPEA/INPES, 1976.

PETRONE, Maria Thereza Schorer. A lavoura canavieira em São Paulo: expansão e declínio (1765-1851). São Paulo: Difusão Europeia do Livro, 1968.

SALLES, Ricardo. E o Vale era o escravo. Rio de Janeiro: Civilização Brasileira, 2008.

SAMARA, Eni de Mesquita. As mulheres, o poder e a família. São Paulo: Marco Zero, 1989.

Paulista, 1977.

O papel do agregado na região de Itu, 1780-1830. São Paulo: Museu

Anos 90, Porto Alegre, v. 23, n. 44, p. 231-263, dez. 2016 
SCHWARTZ, Stuart B. Segredos internos: engenhos e escravos na sociedade colonial 1550-1835. São Paulo: Companhia das Letras, 1988.

SLENES, Robert W. Na senzala uma flor - esperanças e recordações na formação da família escrava: Brasil Sudeste, século XIX. Rio de Janeiro: Nova Fronteira, 1999. TOMICH, Dale. Contested terrains: houses, provision grounds \& the reconstitution of labour in Post-Emancipation Martinique. In: TURNER, Mary (Ed.). From chattel slaves to wage slaves: the dynamics of labour bargaining in the Americas. Bloomington: Indiana University Press; Kingston: Ian Randle; London: James Curry, 1995. p. 241-257.

VERGUEIRO, Nicolau Pereira de Campos. História da fábrica de Ipanema e defesa perante o Senado. Brasília, DF: Senado Federal, 1979.

WITTER, José Sebastião. Ibicaba revisitada. In: SZMRECSÁNYI, Tamás; LAPA, José Roberto do Amaral (Org.). História econômica da independência e do império: coletânea de textos apresentados no I Congresso Brasileiro de História Econômica (Campus da USP, setembro de 1993). São Paulo: Hucitec; Fapesp, 1996. p. 99-130.

Recebido em: 14/01/2016

Aprovado em: 20/07/2016 